\title{
317.
}

\section{NOTE ON THE TRANSFORMATION OF A CERTAIN DIFFERENTIAL EQUATION.}

[From the Philosophical Magazine, vol. xxıII. (1862), pp. 266, 267.]

THE differential equation

$$
\left(1+\theta^{2}\right) \frac{d^{2} y}{d \theta^{2}}+\theta \frac{d y}{d \theta}-m^{2} y=0
$$

if we put therein $i \theta=2 x^{2}+1(i=\sqrt{-1}$ as usual), becomes

$$
\left(1+x^{2}\right) \frac{d^{2} y}{d x^{2}}+x \frac{d y}{d x}-4 m^{2} y=0 .
$$

In fact an integral of the second equation is $\left(\sqrt{1+x^{2}}+x\right)^{2 m}$; this is

$$
=\left(\sqrt{\left(2 x^{2}+1\right)^{2}-1}+2 x^{2}+1\right)^{m} ;
$$

or putting $i \theta=2 x^{2}+1$, it is

which is

$$
=\left(\sqrt{-\theta^{2}-1}+i \theta\right)^{m}
$$

$$
=\left\{i\left(\sqrt{\theta^{2}+1}+\theta\right)\right\}^{m}
$$

so that an integral of the transformed equation in $\theta$ is

$$
=\left(\sqrt{\theta^{2}+1}+\theta\right)^{m}
$$

and writing in the second equation $\theta$ for $x$, and $\frac{1}{2} m$ for $m$, we see that the lastmentioned function, viz. $\left(\sqrt{\theta^{2}+1}+\theta\right)^{m}$, is an integral of

$$
\left(1+\theta^{2}\right) \frac{d^{2} y}{d \theta^{2}}+\theta \frac{d y}{d \theta}-m^{2} y=0
$$


whence the transformed equation in $\theta$ must be this very equation, that is, it must be the first equation. I have for shortness used the particular integral $\left(\sqrt{1+x^{2}}+x\right)^{2 m}$; but the reasoning should have been applied, and it is in fact applicable, without alteration, to the general integral

$$
C\left(\sqrt{1+x^{2}}+x\right)^{m}+C^{\prime}\left(\sqrt{1+x^{2}}-x\right)^{m} .
$$

There is of course no difficulty in a direct verification. Thus, starting from the first equation, or equation in $\theta$, the relation $i \theta=2 x^{2}+1$ gives

$$
\begin{gathered}
\frac{d y}{d \theta}=\frac{i}{4 x} \frac{d y}{d x}, \quad \frac{d^{2} y}{d \theta^{2}}=\frac{i}{4 x} \frac{d}{d x}\left(\frac{i}{4 x} \frac{d y}{d x}\right)=-\frac{1}{16 x^{2}}\left(\frac{d^{2} y}{d x^{2}}-\frac{1}{x} \frac{d y}{d x}\right), \\
1+\theta^{2}=-4 x^{2}\left(1+x^{2}\right)
\end{gathered}
$$

so that the equation becomes

$$
\frac{1}{4}\left(1+x^{2}\right)\left(\frac{d^{2} y}{d x^{2}}-\frac{1}{x} \frac{d y}{d x}\right)+\frac{1+2 x^{2}}{4 x} \frac{d y}{d x}-m^{2} y=0
$$

or multiplying by 4 ,

$$
\left(1+x^{2}\right) \frac{d^{2} y}{d x^{2}}+\left(-\frac{1+x^{2}}{x}+\frac{1+2 x^{2}}{x}\right) \frac{d y}{d x}-4 m^{2} y=0
$$

that is

$$
\left(1+x^{2}\right) \frac{d^{2} y}{d x^{2}}+x \frac{d y}{d x}-4 m^{2} y=0,
$$

the second equation. But the first method shows the reason why the two forms are thus connected together.

2, Stone Buildings, W.C., February 19, 1862. 